\title{
Correlation between significant asymptomatic carotid artery stenosis and severity of peripheral arterial occlusive disease in the lower limb: a retrospective study on 200 patients
}

\author{
Zhongjie Pan, Ruitao Wang, Li Li and Hua Zhang*
}

\begin{abstract}
Background: The aim of this study was to evaluate the correlation between significant asymptomatic carotid artery stenosis (ACAS) and severity of peripheral arterial occlusive disease (PAOD) in the lower limb, and to investigate the risk factors for significant ACAS in patients with lower limb PAOD.

Methods: Two hundred patients with lower limb PAOD were retrospectively reviewed. Baseline data, medical history and potential risk factors were collected. Lower limb PAOD was classified as stage IIA, stage IIB, stage III and stage IV. The carotid artery stenosis was classified as significant ACAS and non-significant ACAS. Multiple logistic regression estimated odds ratio of the risk factors.

Results: Compared to patients with non-significant ACAS, the patients with significant ACAS were significantly older in age and had greater percentage of cigarette-smoking andalcohol beverage consumption, and higher levels of total cholesterol and fibrinogen. There was no significant difference in sex, diabetes, hypertension, coronary heart disease and triglyceride between the two groups. The prevalence rate of significant ACAS increased with the stage of lower limb PAOD and with age. Advanced age and hypercholesteremia were risk factors for significant ACAS in this cohort. The prevalence rate of stroke increased with ACAS stage.

Conclusion: The results suggested that the prevalence rate of significant ACAS was positively correlated with the severity of lower limb PAOD and age. Advanced age and hypercholesteremia appeared to be potential risk factors for significant ACAS in patients with lower limb PAOD.
\end{abstract}

Keywords: Arteriosclerosis, Carotid stenosis, Stroke

\section{Background}

Arteriosclerosis is a systemic vascular disease with carotid artery and lower limb artery as predilection sites. Asymptomatic carotid artery stenosis (ACAS) refers to presence of internal carotid/carotid bifurcation stenotic or occlusive lesions in patients without signs or symptoms of cerebrovascular disease [1]. ACAS is commonly seen in clinical practice and its diagnosis rate is increasing with assistance of modern imaging technique [2].

\footnotetext{
* Correspondence: zhanghua97613@163.com

Vascular Department, Tianjin Union Medical Center, No.190, Jieyuan Road, Hongqiao District, Tianjin 300121, China
}

The incidence rate of peripheral arterial occlusive disease (PAOD) is reported to be $10 \%$ in people above 65 years old in European, and $15-20 \%$ in the population above 70 years old [3]. With an aging population and a changing dietary habit, incidence of peripheral arterial occlusive disease (PAOD) is increasing in China [4]. The incidence rate of lower limb PAOD is around $15.91 \%$ in people above 60 years old [5]. Carotid artery stenosis and lower limb PAOD usually share the same pathological changes and can co-exist. Serious ACAS and complete occlusion of carotid artery could result in fatal cerebrovascular events. It is meaningful to investigate

(c) The Author(s). 2019 Open Access This article is distributed under the terms of the Creative Commons Attribution 4.0 International License (http://creativecommons.org/licenses/by/4.0/), which permits unrestricted use, distribution, and reproduction in any medium, provided you give appropriate credit to the original author(s) and the source, provide a link to the Creative Commons license, and indicate if changes were made. The Creative Commons Public Domain Dedication waiver (http://creativecommons.org/publicdomain/zero/1.0/) applies to the data made available in this article, unless otherwise stated. 
the prevalence of significant ACAS and its risk factors in patients with lower limb PAOD. Thus, it may help for optimal screening and managing significant ACAS in clinical practice.

There are many reports on the correlation between general PAOD and ACAS and a few studies [1, 6-8] focusing on the population with lower limb PAOD. It would be clinically meaningful to obtain a better knowledge of the risk factors for significant ACAS in patients with lower limb PAOD. Therefore, this study retrospectively reviewed the patients with peripheral arterial occlusive disease in lower extremities, in order to evaluate the correlation between the prevalence of significant ACAS and the severity of lower limb PAOD. We further investigated the risk factors for significant ACAS in patients with lower limb PAOD.

\section{Patients and methods}

\section{Patients}

This study was approved by the ethic committee of our hospital. The patients with peripheral arterial occlusive disease in lower extremities who were admitted to our hospital between October 2013 and October 2015 were retrospectively reviewed. The inclusion criteria were patients with symptoms of intermittent claudication, rest pain and/or gangrene; peripheral arterial occlusive disease confirmed by duplex sonography, magnetic resonance angiography or digital subtraction angiography during the admission; patients with carotid artery stenosis confirmed by color doppler imaging during the admission. The exclusion criteria were patients with ischemic stroke history, patients with a history of carotid artery disease, patients allergic to contrast agent, patients with combined heart, liver and/or kidney disease, patients with artery stenosis caused by non-arteriosclerosis, and patients with blood coagulation disorder. For diagnosis of lower limb PAOD, all patients underwent duplex sonography, magnetic resonance angiography or digital subtraction angiography. Color doppler imaging was performed to diagnose ACAS and evaluate the plaque characteristics. For the asymptomatic carotid stenosis patients with mild or moderate stenosis, they were firstly managed medically with drug including high-intensity statin, antithrombotic agents and blood pressure control, and lifestyle changes including smoking cessation and low-fat diet.

\section{Data collection}

Detailed baseline data and medical history were retrospectively collected from the medical records, including sex, age and potential risk factors [9] including coronal heart disease, hypertension, diabetes, hyperlipidaemia, hyperfibrinogenemia, cigarette-smoking and alcoholbeverage drinking history. Risk factors were defined as the following. Coronary heart disease was defined as patients with a relevant medical history and who are receiving relevant/appropriate treatment for this. Hypertension was defined as systolic pressure $>140 \mathrm{mmHg}$ and diastolic pressure $>90 \mathrm{mmHg}$. The diabetes was defined as plasma glucose level $\geq 7.0 \mathrm{mmol} / \mathrm{l} \quad(126 \mathrm{mg} / \mathrm{dl})$; plasma glucose $\geq 11.1 \mathrm{mmol} / \mathrm{l}(200 \mathrm{mg} / \mathrm{dl}) 2 \mathrm{~h}$ after a $75 \mathrm{~g}$ oral glucose load as in a glucose tolerance test; symptoms of high blood sugar and casual plasma glucose $\geq 11.1 \mathrm{mmol} / \mathrm{l}(200 \mathrm{mg} / \mathrm{dl})$; glycated hemoglobin $(\mathrm{HbA1C}) \geq 48 \mathrm{mmol} / \mathrm{mol}$. The hyperlipidemia was defined as the total cholesterol $>6.2 \mathrm{mmol} / \mathrm{L}$ after $12-14 \mathrm{~h}$ fasting. Hyperfibrinogenemia was defined as fibrinogen $>4.0 \mathrm{~g} / \mathrm{L}$. Cigarette-smoking was defined as a history of having at least one cigarette a day. Alcoholbeverage drinking was defined as a history of having at least $50 \mathrm{ml}$ alcohol beverage a day.

Lower limb PAOD was classified into stage I-IV according to Fontaine R [10]. Stage I: asymptomatic and incomplete blood vessel obstruction. Stage II: mild claudication pain in limb. Stage IIA: claudication when walking a distance of greater than $200 \mathrm{~m}$. Stage IIB: claudication when walking a distance of less than $200 \mathrm{~m}$. Stage III: rest pain, mostly in the feet. Stage IV: necrosis and/or gangrene of the limb. The patients in stage IIB, III and IV were treated with arterial angioplasty or artificial artery transplantation; the patients in stage IIA were treated with drugs rather than surgery.

The carotid artery stenosis was classified according to Mannheim intima-media thickness consensus [11]. It was considered as arteriosclerotic plaque if the thickness between the media-adventitia interface and the intimalumen interface was above $1.5 \mathrm{~mm}$. Plaques were further classified as soft plaque, hard plaque, flat plaque and ulcerated plaque, with the first two considered as stable and the last two as unstable plaque according to previous reports $[11,12]$. The severity of carotid artery stenosis was classified as mild (stenosis $\leq 50 \%$ ) with peak systolic velocities $(\mathrm{PSV})=125 \mathrm{~cm} / \mathrm{s}$ and $\mathrm{PSV}_{\mathrm{ICA}} / \mathrm{PSV}_{\mathrm{CCA}}$ ratio $<2.0$, moderate $(50 \%<$ stenosis $<70 \%)$ with PSV between 125 and $230 \mathrm{~cm} / \mathrm{s}$ and $\mathrm{PSV}_{\mathrm{ICA}} / \mathrm{PSV}_{\mathrm{CCA}}$ ratio between 2.0 and 4.0 , serious $(70 \% \leq$ stenosis $<99 \%)$ with $\mathrm{PSV}>230 \mathrm{~cm} / \mathrm{s}$ and $\mathrm{PSV}_{\mathrm{ICA}} / \mathrm{PSV}_{\mathrm{CCA}}$ ratio $>4.0$, and complete occlusion [13]. In this study, the patients with stenosis $\geq 70 \%$ were classified as significant ACAS and patients with stenosis $<70 \%$ as non-significant ACAS.

\section{Statistical analysis}

Statistical analysis was performed using SPSS 19.0 (SPSS Inc., Chicago, IL, USA). Data were presented as mean \pm SD for continuous variables, and frequencies with percentages for categorical variables. Pearson $x^{2}$ test was used for categorical variables in the two cohorts and independent $\mathrm{t}$-test for continuous variables. A binary 
Table 1 Comparison of potential risk factors between patients with significant ACAS and those with non-significant ACAS

\begin{tabular}{llll}
\hline Factors & $\begin{array}{l}\text { Non-significant ACAS } \\
(153 \text { cases })\end{array}$ & $\begin{array}{l}\text { Significant ACAS } \\
\text { (47 cases) }\end{array}$ & $\begin{array}{c}\text { P-value } \\
\text { Age (years) }\end{array}$ \\
Sex (male) & $58.5 \pm 8.5$ & $72.9 \pm 9.1$ & $0.032^{*}$ \\
Cigarette-smoking & $105(68.6 \%)$ & $26(55.3 \%)$ & 0.093 \\
Diabetes & $120(78.7 \%)$ & $46(97.9 \%)$ & $<0.001^{*}$ \\
Hypertension & $142(92.8 \%)$ & $46(97.9 \%)$ & 0.294 \\
Coronary heart disease & $135(88.2 \%)$ & $45(95.7 \%)$ & 0.133 \\
Alcohol-beverage drinking & $148(96.7 \%)$ & $18(38.3 \%)$ & 0.707 \\
Triglyceride (mmol/L) & $127(83.0 \%)$ & $45(95.7 \%)$ & $<0.001^{*}$ \\
Total cholesterol (mmol/L) & $1.33 \pm 0.55$ & $1.37 \pm 0.53$ & 0.618 \\
Fibrinogen $(\mathrm{g} / \mathrm{L})$ & $4.63 \pm 0.96$ & $5.02 \pm 1.12$ & $0.025^{*}$ \\
\hline ACAS Asympto & $4.18 \pm 1.05$ & $0.038^{*}$ \\
\hline
\end{tabular}

ACAS Asymptomatic carotid artery stenosis

*Significant $P$ value

logistic regression further estimated the odds ratio of the risk factors. $P$ value $<0.05$ indicated statistically significant.

\section{Results}

Two hundred patients (131 males and 69 females) met the enrollment criteria and were reviewed. According to Fontaine R's classification [10] for lower limb PAOD, there were 80 cases of stage IIA, 64 cases of stage IIB, 33 cases of stage III and 23 cases of stage IV. As for carotid artery stenosis, there were 94 cases of mild ACAS (47.0\%; 68 males and 26 females), 59 cases of moderate ACAS (29.5\%; 37 males and 27 females), 44 cases of serious (22.0\%; 24 males and 20 females) and 3 cases of complete occlusion (1.5\%; 2 males and 1 female).

Compared with patients with non-significant ACAS, the patients with significant ACAS were significantly older in age, and had greater percentage of cigarettesmoking and alcohol-beverage consumption, and higher level of total cholesterol and fibrinogen $(P<0.05$; Table 1). There was no significant difference in sex, diabetes, hypertension, coronary heart disease and triglyceride between the two groups $(P>0.05)$.

The prevalence of significant ACAS increased with the stage of lower limb PAOD $\left(X^{2}=28.2, P=3.17 \times 10^{-6}\right.$;
Table 2). It also increased with age $\left(\chi^{2}=7.78, P=0.020\right.$; Table 3). Multi-variate logistic regression showed advanced age and hypercholesteremia were independent risk factors for significant ACAS in patients with lower limb PAOD (Table 4).

\section{Discussion}

In the present study, we found that the prevalence rate of significant ACAS increased with the stage of lower limb PAOD. It also increased with age. Multi-variate logistic regression showed advanced age and hypercholesteremia were independent risk factors for significant ACAS. In the patients above 70 years old, the percentage of significant ACAS is $32.10 \%$, which was significantly higher $(P<0.05)$ than those below 70 years old. Among the patients with lower limb PAOD under stage IV, there were 12 cases of significant ACAS (12/23, 52.2\%) and it was higher than patients in other stages. But Mirsharifi R's research [14] pointed out that carotid artery stenosis had correlation with diabetes, hypertension, dyslipidemia, coronary heart disease and ABI, while it had nothing to do with age. Pilcher J et al. [15] studied 200 cases of PAOD and reported that there was no correlation between the degree of carotid artery stenosis

Table 2 The incidence rate of significant ACAS increased with the stage of lower limb PAOD

\begin{tabular}{|c|c|c|c|c|c|}
\hline \multirow{2}{*}{$\begin{array}{l}\text { Lower limb } \\
\text { PAOD }\end{array}$} & \multicolumn{2}{|l|}{ ACAS (\%) ${ }^{\mathrm{a}}$} & \multirow[t]{2}{*}{ Total number } & \multirow[t]{2}{*}{$P$-value ${ }^{b}$} & \multirow{2}{*}{$\begin{array}{l}\text { Odds ratios (95\% } \\
\text { confidence interval) }\end{array}$} \\
\hline & Non-significant & Significant & & & \\
\hline Stage IIA & $72(90.0 \%)$ & $8(10.0 \%)$ & 80 & $<0.001^{*}$ & $0.362(0.188-0.695)$ \\
\hline Stage IIB & $52(81.3 \%)$ & $12(18.8 \%)$ & 64 & 0.277 & $0.751(0.440-1.284)$ \\
\hline Stage III & $18(54.6 \%)$ & 15 (45.5\%) & 33 & $0.001^{*}$ & $2.713(1.485-4.954)$ \\
\hline Stage IV & $11(47.8 \%)$ & $12(52.2 \%)$ & 23 & $0.001^{*}$ & $3.551(1.677-7.518)$ \\
\hline Total number & 153 & 47 & 200 & & \\
\hline
\end{tabular}

ACAS Asymptomatic carotid artery stenosis, PAOD Peripheral arterial occlusive disease

* Significant $P$-value

${ }^{a} X^{2}=28.2, P=3.17 \times 10^{-6} ;$ Spearman's rho $=0.352, P=3.13 \times 10^{-7}$

${ }^{\mathrm{b}}$ After Bonferroni correction $\mathrm{a}^{\prime}=0.013$ 
Table 3 The incidence rate of significant ACAS increased with the age of the patients

\begin{tabular}{|c|c|c|c|c|c|}
\hline \multirow[t]{2}{*}{ Age } & \multicolumn{2}{|l|}{ ACAS $(\%)^{a}$} & \multirow[t]{2}{*}{ Total number } & \multirow[t]{2}{*}{$P$-value ${ }^{b}$} & \multirow{2}{*}{$\begin{array}{l}\text { Odds ratios ( } 95 \% \\
\text { confidence } \\
\text { interval) }\end{array}$} \\
\hline & Non-significant & Significant & & & \\
\hline $50-59$ & $38(90.5 \%)$ & $4(9.5 \%)$ & 42 & $0.016^{*}$ & $0.343(0.129-0.910)$ \\
\hline $60-69$ & $62(77.5 \%)$ & $18(22.5 \%)$ & 80 & 0.785 & $0.945(0.627-1.425)$ \\
\hline$\geq 70$ & $53(68.0 \%)$ & 25 (32.1\%) & 78 & $0.023^{*}$ & $1.536(1.087-2.169)$ \\
\hline Total number & 153 & 47 & 200 & & \\
\hline
\end{tabular}

ACAS Asymptomatic carotid artery stenosis

* Significant $P$-value

${ }^{\mathrm{a}} \mathrm{X}^{2}=7.78, P=0.020 ;$ Spearman's rho $=0.194, P=0.006$

${ }^{b}$ After Bonferroni correction $\alpha^{\prime}=0.017$

and lower limb arteriosclerosis. Marek et al's [16] study showed the carotid artery stenosis $\geq 50 \%$ had close correlation with age $>65$ years old, $\mathrm{ABI}<0.7$ and carotid bruit. Mirsharifi et al. [14] reported that carotid artery stenosis was correlated with diabetes, hypertension, hyperlipidemia, coronary heart disease, severity of presenting symptom and ABI, and it had significant association with age. Song et al. [8] also evaluated the prevalence of asymptomatic carotid artery stenosis in patients with lower extremities PAOD from Peking Union Medical College Hospital. They found that the prevalence of asymptomatic carotid artery stenosis was higher in patients with lower extremities PAOD, which was in accordance with our results. Smoking, coronary artery disease and hypertension were related risk factors in their study while in our study there was no significant difference in hypertension and coronary heart disease between the two groups $(P>0.05)$. We thought that this difference might be due to the characteristics of the study population and the sample size.

In this study, the percentage of significant ACAS increased with the severity of lower limb PAOD $(P<0.05)$, which was in accordance with previous report [17]. Therefore, screening for significant ACAS in lower limb PAOD is important, especially in those patients with risk factors. In this regard, it may benefit the patients with

Table 4 Multi-variate logistic regression of the risk factors for significant asymptomatic carotid artery stenosis

\begin{tabular}{llll}
\hline Factors & $\beta$ & OR $(95 \% \mathrm{Cl})$ & $P$-value \\
\hline Age & 0.076 & $1.079(1.055-1.104)$ & $0.042^{*}$ \\
Sex & 0.694 & $1.352(0.933-1.959)$ & 0.114 \\
Cigarette-smoking & 0.353 & $1.325(0.926-1.872)$ & 0.182 \\
Alcohol-beverage drinking & 0.345 & $1.415(0.913-1.866)$ & 0.126 \\
Hypertension & 0.852 & $2.423(1.225-4.449)$ & 0.063 \\
Diabetes & 0.488 & $1.565(0.954-1.568)$ & 0.081 \\
Coronary heart disease & 0.455 & $1.576(0.977-1.732)$ & 0.667 \\
Hypercholesteremia & 0.546 & $2.013(1.076-3.325)$ & $0.033^{*}$ \\
Hyperlipidemia & -0.077 & $0.964(0.832-1.213)$ & 0.972 \\
\hline
\end{tabular}

*Significant $P$-value more severe PAOD to get screened regularly for ACAS. Thus, proper preventive measures could be taken in time to even reduce morbidity or stroke prevalence. It is meaningful in clinical screening especially when the prevalence of PAOD is increasing in China [4].

\section{Conclusions}

There are some limitations in this study, such as small sample size and single center. It is necessary to perform a further study with a larger sample in multiple centers. Besides, the generalizability of the study results is limited because the study participants are only Chinese people in North China. In conclusion, the prevalence of significant ACAS increased with the severity of lower PAOD and age. Advanced age and hypercholesteremia were potential risk factors for significant ACAS in patients with lower limb PAOD. We suggest that patients with lower limb PAOD and the potential risk factors may benefit from the screening for significant ACAS.

\section{Abbreviations \\ ACAS: Asymptomatic carotid artery stenosis; PAOD: Peripheral arterial occlusive disease}

\section{Acknowledgements}

None.

Authors' contributions

ZP was responsible for study design and participated in data collection, data analysis, data interpretation and manuscript drafting; RW participated in data collection, data analysis, manuscript drafting and literature research; LL participated in data analysis, data interpretation, manuscript preparation and literature research. $\mathrm{HZ}$ participated in study design and was responsible for data interpretation, manuscript revising and submission. All authors approved the final version of the manuscript and agree to be accountable for all aspects of the work in ensuring the accuracy or integrity of the work.

\section{Funding}

This study was funded by Tianjin Municipal Planning Commission of science and Research Fund (2015KZ062) and Tianjin Union Medical Center Funding 2018 YJ008 during the major revisions and minor revision.

\section{Availability of data and materials}

The data and materials are available if required.

\section{Ethics approval and consent to participate}

This study was approved by the ethic committee of Tianjin Union Medical Center and all signed informed consents of the patients were obtained. 


\section{Consent for publication}

Not applicable.

\section{Competing interests}

The authors declare that they have no competing interests.

Received: 31 July 2018 Accepted: 9 October 2019

Published online: 28 October 2019

\section{References}

1. RanciÄ Z, Radak D, StojanoviÄ D. Early detection of asymptomatic carotid disease in patients with obliterative arteriosclerosis of the lower extremities. Srp Arh Celok Lek. 2002;130(7-8):258-64.

2. Chambers BR, Roberts NG. Asymptomatic carotid artery stenosis. Arch Neurol. 2007;9(2):81-9.

3. Storck M, Wagner HJ. Peripheral arterial obstruction and acute lower limb ischemia. Chirurg. 2007;78(7):611-9.

4. Kannel WB. The demographics of claudication and the aging of the American population. Vasc Med. 1996;1(1):60-4.

5. Mitsumori LM, Hatsukami TS, Ferguson MS, Kerwin WS, Cai J, Yuan C. In vivo accuracy of multisequence MR imaging for identifying unstable fibrous caps in advanced human carotid plaques. J Magn Reson Imaging. 2003;17(4): 410-20.

6. Cinà CS, Safar HA, Maggisano R, Bailey R, Clase CM. Prevalence and progression of internal carotid artery stenosis in patients with peripheral arterial occlusive disease. J Vasc Surg. 2002;36(1):75-82.

7. Sirico G, Spadera L, De LM, Brevetti G. Carotid artery disease and stroke in patients with peripheral arterial disease. The role of inflammation. Monaldi Arch Chest Dis. 2009;72(1):10-7.

8. Song XT, Liu B, Liu CW, Ni L, Zeng R, Ye W, Zheng YH, Li YJ. Prevalence of asymptomatic carotid artery stenosis in patients with arteriosclerosis obliterans of lower extremities and risk factor analysis. Zhonghua Yi Xue Za Zhi. 2016;96(2):126.

9. Weerd MD, Greving JP, Jong AWFD, Buskens E, Bots ML. Prevalence of asymptomatic carotid artery stenosis according to age and sex systematic review and metaregression analysis. Stroke. 2009;40(4):1105-13.

10. Fontaine R, Kim M, Kieny R. Surgical treatment of peripheral circulation disorders. Helvetica Chirurgica Acta. 1954;21 (5-6):499.

11. Touboul PJ, Hennerici MG, Meairs S, Adams H, Amarenco P, Desvarieux M, Ebrahim S, Fatar M, Hernandez HR, Kownator S. Mannheim intima-media thickness consensus. Cerebrovasc Dis. 2004;18(4):346.

12. Turkenburg $\mathrm{J}$, van Oostayen JA, Bollen WL. Role of carotid sonography as a first examination in the evaluation of patients with transient ischemic attacks and strokes: benefit in relation to age. J Clin Ultrasound. 1999;27(2):65.

13. Adams RJ, Chimowitz MI, Alpert JS, Awad IA, Cerqueria MD, Fayad P. Taubert KA. Coronary risk evaluation in patients with transient ischemic attack and ischemic stroke: a scientific statement for healthcare professionals from the Stroke Council and the Council on Clinical Cardiology of the American Heart Association/American Stroke Association. Circulation. 2005:108(10):1278-90.

14. Mirsharifi R, Karimian F, Farahmand MR, Aminian A. Asymptomatic carotid artery stenosis in patients with severe peripheral vascular diseases. J Res Med Sci. 2009;14(2):117.

15. Pilcher JM, Danaher J, Khaw KT. The prevalence of asymptomatic carotid artery disease in patients with peripheral vascular disease. Clin Radiol. 2000; 55(1):56.

16. Marek J, Mills JL, Harvich J, Cui H, Fujitani RM. Utility of routine carotid duplex screening in patients who have claudication. J Vasc Surg. 1996;24(4): 572-9.

17. Yun WS, Young-Nam R, Ui-Jun P, Kyung-Bok L, Dong-lk K, Young-Wook K. Prevalence of asymptomatic critical carotid artery stenosis in Korean patients with chronic atherosclerotic lower extremity ischemia: is a screening carotid duplex ultrasonography worthwhile? J Korean Med Sci. 2010;25(8):1167-70.

\section{Publisher's Note}

Springer Nature remains neutral with regard to jurisdictional claims in published maps and institutional affiliations.

\section{Ready to submit your research? Choose BMC and benefit from:}

- fast, convenient online submission

- thorough peer review by experienced researchers in your field

- rapid publication on acceptance

- support for research data, including large and complex data types

- gold Open Access which fosters wider collaboration and increased citations

- maximum visibility for your research: over $100 \mathrm{M}$ website views per year

At $\mathrm{BMC}$, research is always in progress.

Learn more biomedcentral.com/submissions 